\title{
HIGH LINE PARK E ELEVADO COSTA E SILVA: ABORDAGEM SIMILAR, REALIDADES DISTINTAS.
}

\author{
André Martins Nogueira
}

\begin{abstract}
RESUMO: A comparação do High Line Park, em Nova lorque, EUA, com o Elevado Costa e Silva, em São Paulo, Brasil, tem sido constantemente exposta nos debates e audiências públicas de maneira bastante superficial, evidenciando a globalização como fenômeno presente e influente no enfrentamento das principais questões das metrópoles contemporâneas. Este artigo contrapõe o argumento de que o sucesso do primeiro poderá ser alcançado com a "tropicalização" dos resultados em intervenção semelhante no segundo, inúmeras vezes citado em debates públicos. Inicialmente consideraram-se abordagens de semelhança presentes nas cidades globais, tais como descontinuidades, rupturas, fragmentações, fluxos, desvalorização imobiliária e constituição da paisagem urbana, entre outros, para compreender o fenômeno da globalização no contexto abordado. Posteriormente, realizaram-se visitas "in loco", para reconhecimento de ambos os territórios como lugares únicos, carentes de ações específicas locais, inerentes à cultura local, e, portanto, não transferíveis para outras realidades. Por fim, o trabalho inseriu o Elevado dentro do contexto global de transformação de estruturas urbanas pós-industriais, com a sugestão de elaboração de leitura específica deste território através da análise composta por equipe multidisciplinar.
\end{abstract}

Palavras-chave: via elevada, metrópole contemporânea, contexto urbano.

\section{HIGH LINE PARK E ELEVADO COSTA E SILVA: SIMILAR APPROACH, DIFFERENT REALITIES.}

\begin{abstract}
The comparison of the High Line Park in New York, USA, with the Elevado Costa e Silva, in Sao Paulo, Brazil, is repeatedly quoted in public debates with shallow foundations, exposing in a certain way globalization as present and influential phenomenon in addressing the key issues of the contemporary metropolis. This article contrasts the argument that the success of the first can be reached with the "tropicalization" of the results in a similar intervention over the second. Firstly, similar approaches presented in global cities such as discontinuities, breaks, fragmentation, flows, real estate depreciation and constitution of the urban landscape, among others, where used in both cases, in

\footnotetext{
${ }^{1}$ Arquiteto e Urbanista pela Universidade Presbiteriana Mackenzie, Pós-Graduado em Geografia, Cidade e Arquitetura pela Associação Escola da Cidade em Arquitetura e Urbanismo, atual mestrando pela Universidade Presbiteriana Mackenzie.

andremartinsnogueira@gmail.com.
} 


\section{Revista Nacional de}

Gerenciamento de Cidades

order to understand the globalization influence over this scenario. Secondly, through visits "in loco", both territories were analyzed as single places with specific actions, inherent to the local culture, and therefore not transferable to other realities. Finally, this paper debates the Elevado within the global context of transformation of post-industrial urban structures, with the suggestion to the development of specific research of its territory, based in a multidisciplinary team analysis.

Key words: highline, contemporary metropolis, urban landscape.

\section{HIGH LINE PARK E ELEVADO COSTA E SILVA: ENFOQUE SIMILAR, DIFERENTES REALIDADES.}

RESUMEN: La comparación del parque High Line en Nueva York, EE.UU., con el Elevado Costa e Silva, en Sao Paulo, Brasil, ha sido constantemente expuesta en los debates públicos superficialmente, demostrando la globalización como fenómeno presente e influyente en el tratamiento de las cuestiones claves de las metrópolis contemporáneas. El propósito de este artículo es argumentar en contra de que el éxito de la primera se puede alcanzar con la "tropicalización" de los resultados en una intervención similar en el segundo (argumento presentado en muchos debates públicos). Inicialmente consideraron enfoques similares presentes en las ciudades globales como discontinuidades, rupturas, la fragmentación, los flujos, la depreciación de bienes raíces y constitución del paisaje urbano, entre otros, para la discusión del fenómeno de la globalización en el contexto abordado. Posteriormente, hubo visitas "in loco" para reconocer ambos territorios como lugares únicos, carente de acciones locales específicas inherentes a la cultura local, y por lo tanto no transferibles a otras realidades. Por último, el trabajo direcciona el Elevado dentro del contexto global de transformación de las estructuras urbanas postindustriales, con la sugerencia de elaborar investigación específica compuesta por un equipo multidisciplinario de análisis en este territorio.

Palabras-clave: via elevada, metrópolis contemporánea, contexto urbano.

\section{INTRODUÇÃO}

Atualmente, passamos por um processo de revisão e experimentação no desenvolvimento urbano mundial, que enfrenta as consequências do rápido crescimento urbano aliado à falta de planejamento e planos urbanísticos, principalmente em países em desenvolvimento.

Somos os primeiros a construir uma civilização global e, portanto, os primeiros que enfrentam, simultaneamente, a expansão da população, a destruição dos recursos naturais e a constante perda do meio ambiente natural. Também passamos por um momento de revisão e reflexão sobre que tipo de cidade que queremos viver e/ou (re) produzir (KOOLHAAS, 1997). 
Esta situação aparenta ser uma constante para todas as cidades globais. Os fluxos, usos, e velocidades estão cada vez mais acelerados, assim como as transformações urbanas consequentes desta nova forma de viver. Soma-se a isso, a evolução da tecnologia de comunicação e o fato de vivermos em uma sociedade que está em processo de globalização e simultaneidade, o que gera inconscientemente um efeito de abolição do tempo e do espaço (WAISMAN, 2013), em busca do melhor resultado para as problemáticas que aparentemente estão presentes em qualquer cidade global.

A consequência desta desmaterialização e perda de noção real do território tem sido bastante presente no enfrentamento de problemáticas urbanas. Para Saskia Sassen, 2014, estar fisicamente presente permite a consciência da paisagem urbana muito além da noção de ordem visual e material. Ou seja, existem situações que exigem a retomada desta aproximação tempo-espacial, evitando que temáticas semelhantes sejam encaradas erroneamente através abordagens globais.

Desta maneira, a arquitetura e o urbanismo devem ser renovadores, reparadores e restauradores com o mínimo de impacto ambiental possível (WISNIK, 2009). Devemos costurar estes fragmentos de maneira a restabelecer a continuidade no tecido urbano, perdida em meio a um devaneio errôneo alimentado pelo analfabetismo globalizado, como se fosse uma nova cegueira, criada pelo senso comum estético pertencente ao "estilo capitalista da liberdade individual".

Geralmente, essa assimilação é feita por países em desenvolvimento, assumindo como verdade ações de sucesso em países desenvolvidos, como é o caso da constante citação entre o High Line Park, na Cidade de Nova lorque, EUA, com o futuro do Elevado Costa e Silva, na Cidade de São Paulo, Brasil.

\section{OBJETIVO}

O objetivo deste artigo é promover a discussão sobre a comparação do High Line Park, em Nova lorque, EUA, com o Elevado Costa e Silva, em São Paulo, 


\section{Revista Nacional de}

Gerenciamento de Cidades

Brasil, reconhecendo a globalização como fenômeno presente e influente no enfrentamento das principais questões das metrópoles contemporâneas, e desmistificando a crença de que o sucesso do primeiro poderá ser alcançado com a "tropicalização" dos resultados em intervenção semelhante no segundo.

\section{METODOLOGIA}

O método proposto promoveu a construção de raciocínio lógico a partir da integração dos dados coletados e do aprofundamento da base conceitual crítica. Iniciou-se o projeto por pesquisa e fundamentação teórica através de dados secundários (pesquisa bibliográfica / referências conceituais), que complementaram o olhar sobre o problema. Posteriormente realizaram-se visitas in loco para consequente percepção da realidade de cada território em debate. Em seguida, elaboram-se comparações baseadas em possíveis semelhanças, aspectos de processo e de projeto, considerando o histórico de cada um dos casos. Por fim, com a conclusão reconheceram-se os aspectos essenciais de cada território como fator chave de desenvolvimento para qualquer proposta de intervenção urbana.

\section{RESULTADOS}

Analisar como o High Line foi transformado em um parque urbano de referência mundial é bastante oportuno para fomentar esta discussão, uma vez que o tema das transformações urbanas nas metrópoles contemporâneas tem sido foco de grandes debates em diversas oportunidades pelo mundo todo.

O High Line Park é um parque urbano implantado em Nova lorque sobre uma linha férrea elevada construída em 1934, cuja operação se manteve ativa até 1980. Durante 20 anos, a estrutura esteve abandonada, comprometendo o desenvolvimento dos bairros que são permeados por ela (The Meatpacking District, 


\section{Revista Nacional de}

Gerenciamento de Cidades

West Chelsea, Clinton / Hell's Kitchen, West Side Rail Yards). (FRIENDS OF THE HIGH LINE, 2008).

A discussão sobre o futuro da via elevada em Nova lorque sempre esteve presente nas campanhas políticas e decisões do mercado desde sua desativação, em 1980. Porém, seu futuro passou a ganhar direcionamento consolidado a partir de 1999, quando dois moradores de Nova lorque, Joshua David e Robert Hammond, se conheceram em uma reunião local de comunidade, e rapidamente se aproximaram pelo interesse comum de intervir no local (HAMMOND; DAVID, 2011).

Ambos tinham grande fascinação pela linha elevada, e viram nela possibilidades de transformação e criação de uma nova maneira de se viver a cidade. A partir de então, tomaram inúmeras iniciativas em busca de sua preservação, até então constantemente ameaçada, e consequente reforma. Em conjunto, criaram a Associação Friends of High Line, com o objetivo de garantir ocupação pública de sua extensão como um todo, transformando o vazio urbano em um parque elevado.

A associação foi responsável pela elaboração de inúmeras atividades e encontros, buscando participação de todos envolvidos. Trabalhou constantemente para manter o espirito comunitário ativo e integrado, com o objetivo de entender a realidade e o impacto que a estrutura tinha no cotidiano daqueles que ali habitavam, além de sua influencia sobre a cidade como um todo. A dupla promoveu debates estratégicos sobre o futuro da via, visando integração entre os interesses públicos e privados. Quase sem experiência relacionada ao assunto, conseguiram unir pessoas com bastante expertise nas temáticas abordadas (HAMMOND; DAVID, 2011).

A transformação de uma nesga de cidade industrial ociosa através de maneiras inovadoras de se pensar a cidade foi um resultado consequente de grande esforço e dedicação constante, tanto da população local e regional, quanto de grandes intelectuais, influentes figuras públicas, planejadores renomados, ativistas culturais, órgãos públicos, instituições privadas, entre outros. 
Exemplo de boa relação entre interesses, o parque atraiu olhares do mercado, e transformou a região, sem destruir obrigatoriamente nada. Os ícones arquitetônicos construídos no local contribuíram para o desenvolvimento do entorno e da economia local, e se tornaram parte da "marca" criada para o território.

Essa identidade físico-espacial, bem como a criação de legislação especial, adequada tanto às necessidades locais quanto as necessidades dos investidores, fez com que o High Line se tornasse inspiração para outros movimentos que ativaram maior participação e posicionamento político da comunidade, através da construção da cultura da qualidade e elevado grau de design. Hoje, o parque possui design específico e único, com soluções criativas e inovadoras, e se tornou uma das principais âncoras culturais da cidade.

O projeto do High Line, hoje, reconhece e afirma através de sua materialização, a importância da revisão dos elementos que compõem o cenário urbano de uma cidade em constante desenvolvimento e transformação. Seu ponto de partida foi a consciência coletiva da presença de um vazio urbano que impedia a continuidade e desenvolvimento de uma área da cidade de Nova lorque, completamente degradada, abandonada e vulnerável a manifestações de violência.

Todos esses pontos estão relacionados com o contexto sócio-culturaleconômico-político-legislativo-ambiental da sociedade americana da época. Sendo assim, há de se lembrar de que a realidade brasileira atual é bastante distinta desta apresentada, e que o Elevado Costa e Silva abrange, além de questões semelhantes, outras relacionadas com seu território específico.

Construído durante a gestão de Paulo Maluf, o Elevado foi entregue no aniversário de 417 anos da capital, 25 de janeiro de 1971. Apelidado de Minhocão, o argumento utilizado para justificar sua implantação foi que ele aliviaria o trânsito na região central (ARTIGAS; CASTRO; MELLO, 2008). Contudo, desde antes de sua inauguração, especialistas questionam este posicionamento. Muitos consideram que a obra pouco contribui para essa finalidade, uma vez que na época em que foi 


\section{Revista Nacional de}

Gerenciamento de Cidades

entregue a Marginal não havia nem sido concluída, além de sua capacidade para carros ser insuficiente para a demanda.

Como em qualquer centro metropolitano, existem fatores que foram determinantes para o desenvolvimento histórico da maneira como o conhecemos, ainda que seus respectivos impactos e presença perdurem e se estendam para os demais períodos. Fatores estes que possuem diferentes escalas temporais, podendo influenciar decisões e vivencias a curto, médio e longo prazo: como, por exemplo, a própria construção do Elevado.

Mesmo depois de 45 anos de sua construção, o "Minhocão" permanece como centro das mais relevantes discussões sobre o modelo de projeto urbanístico que pretendemos para a cidade. No foco desse debate coloca-se a questão: o que fazer com este artefato, hoje inadequado às demandas contemporâneas?

$\mathrm{Na}$ época, buscou-se representar com o Elevado grande avanço tecnológico, ainda que de maneira bastante simbólica. Entretanto, é sabido que sua construção está acompanhada de outras decisões fundamentadas em um pensamento equivocado, igualmente retrógrado. Hoje, o Elevado é mais uma prova do desprezo pelo passado e o entusiasmo pela modernidade em busca do progresso, mesmo de modo bastante superficial.

É certo que em alguns momentos, a descontinuidade se apresente como algo positivo, necessário à realidade. Contudo, neste caso, ela veio de maneira tão impactante, rompendo com qualquer valor do passado, que de nenhum modo ela se apresenta como desejável. Muito pelo contrário, ela impediu a consolidação de orientações de desenvolvimento urbano, e formação de um território agradável.

Desde sua inauguração até o presente momento, a cidade sofreu grandes intervenções, tanto na parte civil, quanto na parte jurídica e legislativa. Foram formuladas inúmeras leis que condicionaram - e ainda condicionam - o desenvolvimento urbano, e regem sobre o desenho da cidade.

O Plano de Desenvolvimento Estratégico, sancionado na data 31 de julho de 2014, pelo prefeito Fernando Haddad, evidenciou a via como elemento perturbador 


\section{Revista Nacional de}

Gerenciamento de Cidades

da cidade, arcaico, que deverá ser revisto frente à realidade da Cidade de São Paulo.

A tensão do Elevado como um espaço "entre" pontos aumentou, comprovando que seus limites espaciais se mostram menos rígidos, que vão além de sua abrangência material. Hoje, a discussão sobre o futuro elevado vai além do ponto "A" ao ponto "B"; ultrapassa seu propósito inicial de uma via expressa conectora, e reconhece que a infraestrutura não é mais fundamental para a mobilidade urbana da cidade.

Existem dois planos de ação, opostos entre si, evidenciados no próprio corpo do Plano de Desenvolvimento Estratégico de 2014: a demolição completa e gradual de sua estrutura, ou o reaproveitamento da estrutura existente para a criação de um parque suspenso, cujo projeto ainda não foi elaborado:

Lei específica deverá ser elaborada determinando a gradual restrição ao transporte individual motorizado no Elevado Costa e Silva, definindo prazos até sua completa desativação como via de tráfego, sua demolição ou transformação, parcial ou integral, em parque. (Lei 16.050/2014, Artigo 375.Parágrafo Único).

Com isso, retomou-se fervorosamente a polêmica discussão sobre o futuro da via e da região central, uma vez que o próprio órgão regente não tem claro ainda o que seria a melhor solução, e abre a oportunidade para a discussão e posicionamento público frente à condição descrita na Lei.

Essa dualidade tem sido intensamente debatida pelos órgãos públicos através de audiências marcadas principalmente por cidadãos pertencentes a duas entidades de representação social com objetivos distintos: Associação Parque Minhocão e Veredas.

A entidade Veredas acredita que deva existir uma intensa e ampla discussão com os moradores da região, além de estudos de impacto que o novo empreendimento pode causar na região, para que se tenha suficiente segurança, quando da tomada de uma decisão de grande impacto. Acreditam, sobretudo, que a 


\section{Revista Nacional de}

Gerenciamento de Cidades

definição sobre o uso futuro do Elevado após seu fechamento para o tráfego precisa ser acompanhada de estudos e análises de impacto socioambiental de cada possibilidade, além de consultas publicas para que haja uma real e ativa participação democrática sobre a decisão. Para a entidade, não houve tempo hábil para que este determinado assunto seja questionado e estruturado de forma participativa, e defendem que sejam feitas consultas publicas, em lugares fora da Câmara, para discutir os reais impactos sobre os diferentes usos futuro. Acreditam que assim, conseguirão criar massa crítica e possibilitar com que a população seja mais bem informada sobre as futuras mudanças de seu respectivo bairro.

Oficialmente fundada em 14 de agosto de 2013 pelo engenheiro e empresário Athos Comolatti, a Associação Parque Minhocão, com atual sede Rua General Júlio Marcondes Salgado 65, apartamento 23, tem como objetivo principal a transformação do Elevado Presidente Arthur da Costa e Silva em um parque municipal elevado com destinação multiuso em pró da população da Cidade de São Paulo e demais visitantes.

A Associação defende a promoção de atividades de lazer, esportes, artes plásticas, gastronomia, música, teatro, dança, cinema, fotografia, além de outras atividades que o local comporte. Atualmente, a Associação promove encontros constantes entre todos interessados com o objetivo de apresentar o plano e fomentar debates em torno da melhor solução dentro dos respectivos objetivos.

A entidade ainda não possui projeto, e acredita que este deve ser alvo de um novo concurso de arquitetura, de abrangência nacional, com um programa a ser definido através de consulta direta com moradores da região, além de profissionais atuantes nas disciplinas envolvidas.

Com participação social bastante ativa, Athos Comolatti, atual presidente da Associação, tem se dedicado à coleta de assinaturas para apoiar Projeto de Lei 10/2014, apresentado em Fevereiro deste mesmo ano, que visa à desativação gradual e imediata construção do parque. O projeto dos vereadores Aurélio Nomura (PSDB), Nabil Bonduki (PT), Police Neto (PSD), Toninho Vespoli (PSOL), Ricardo 


\section{Revista Nacional de}

Gerenciamento de Cidades

Young (PPS), Gilberto Natalini (PV), Goulart (PSD) e George Hato (PMDB) é alvo de grande polêmica, e já recebeu uma proposta de substitutivo pela entidade Veredas, que por sua vez defende que, primeiro, seja definido somente o fim da circulação de carros, para posterior discussão sobre o destino final da estrutura: transformação em parque ou demolição completa.

A proposta da Associação "Parque Minhocão" esta evidentemente inspirada no projeto do High Line, em Nova York. Algumas semelhanças como vias elevadas de transporte, grupos sociais ativos contraditórios com organizações a favor da demolição ou da construção de um parque, entorno degradado, etc., são fatores que a principio são bastante convincentes e atrativos.

Sem dúvida, o High Line é uma transformação urbana contemporânea de muito sucesso em parcerias público-privada, exemplo de participação ativa de cidadãos via doações e ações voluntárias, e referência em design paisagístico e ambiental. Todo esse contexto é muito inspirador, e não há como negar que o caminho percorrido por todos envolvidos nesta grande modificação urbana americana (e de impacto global), foi um dos principais fatores que levou ao sucesso de sua implantação e operação.

Contudo, o High Line Park é modelo único e não replicável, inserido em um contexto específico e particular americado. Desde o início da implantação da via elevada, de sua materialidade, proposta inicial, funcionamento e histórico de ocupação, até o começo do processo de transformação - com a formação da Associação Friends of the High Line (1999) - passando por sua implantação (início das obras em 2006) e gestão de operações (desde a inauguração da primeira fase em 2009), o parque carrega ações condizentes com a respectiva realidade.

Apesar de ambas as estruturas estarem elevadas e se posicionarem como suporte para transportes incoerentes com as demandas contemporâneas, os contextos são bastante distintos com processos históricos, culturais, políticos e econômicos diferentes. 
Ou seja, é natural que o peso da herança colonial se faça presente e leve a busca da replica de um modelo de sucesso por uma aparente semelhança. Porém, basta irmos um pouco além e analisarmos a realidade tal qual ela se apresenta para entendermos que não há nenhuma conversa direta entre a situação americana e a brasileira.

A começar pelo fato do Minhocão ser uma via elevada pública sobre solo público, ativa, voltada única e exclusivamente para transporte automobilístico localizada na Região central da cidade de São Paulo, enquanto o High Line era uma via férrea elevada sobre solo privado, inaugurada em 1932, desativada há 20 anos antes de sofrer as primeiras transformações.

Qualquer intervenção no Elevado - seja demolição, seja sua adequação para um parque -acarretará no impacto direto de inúmeras vidas por pertencer a uma região verticalizada com uso predominantemente residencial, térreo comercial, e algumas instituições e edificações de serviço. Enquanto o entorno no caso americano eram galpões industriais abandonados e fábricas, em sua maioria inativas.

Por ser privativo, o acesso à via americana desde o começo era restrito e controlado, e os proprietários de lotes viam a via como impeditivo para parcelamento e ocupação. Já no caso brasileiro, o artefato é público, com acesso ilimitado, restrito por períodos específicos e a opinião dos moradores é heterogênea, não permitindo desta maneira, que seja elaborado qualquer posicionamento comum, ou de maioria.

A materialidade de ambas também é diferente: o HighLine possui um sistema construtivo em estrutura metálica - menor impacto ambiental na transformação enquanto o Minhocão é feito de estrutura de concreto armado - maior impacto ambiental em sua transformação. Isso é fator fundamental para qualquer tomada de decisão, afinal as técnicas e tecnologias são diferentes, exigindo abordagens distintas.

O que se destaca é o processo metodológico de entendimento da problemática para futura tomada de decisão. Além disso, a persistência e 


\section{Revista Nacional de}

Gerenciamento de Cidades

temos a oportunidade de rever estes valores, a luz de uma cidade mais humanitária, e menos maquinaria.

Revitalizar o território deve ser um dos principais conceitos motivadores para a grande intervenção no futuro da região central da Capital. Não se pretende incentivar a gentrificação, ou a produção de artifícios que possam atrair o mercado mobiliário e o boom econômico, mas sim surpreender com melhoria, sem desprezar os humanos que ali residem e as pré-existências geomorfológicas. Reconhece-se a necessidade de inaugurar um novo modo de viver. Ou seja, a discussão deverá trazer, antes de qualquer ação pontual, temáticas em torno da organização espacial, e a fim de reestabelecer as relações dignas que ali se fazem necessárias.

Obviamente, não se pode ter conhecimento completo sobre algo em constante transformação, portanto é a consciência desta mutação também é fator determinante.

Essa consciência reflete na humildade a ponto de saber que somos parte da historia, e não seu ponto final carrega também o conhecimento de que o futuro é imprevisível, assim como as transformações da sociedade. Com isso, o debate deve estar atento às urgências e necessidades destas transformações, capaz de adaptar seus direcionamentos para abraçar de melhor maneira as novas demandas sociais. "Nenhuma cidade jamais aceitará ser cristalizada numa forma e que, portanto, nenhum equilíbrio alcançado poderá constituir um fundamento estável, algo imutável". (DECANDIA, 2003; 192)

O futuro certamente deverá receber neste território uma intervenção que promova, de maneira mais qualitativa, uma extensão dos espaços públicos de São Paulo, atribuindo-Ihe um carácter de uma espécie de quintal coletivo e eliminando o caráter transitório automobilístico. Além disso, já existe uma ocupação de características específicas estabelecida no local bastante presente: um grande desafio para a disciplina arquitetônica absorvê-la em sua proposta - aqui vista como uma arte coletiva e sociopolítica (GRINOVER; RUBINO, 2009, APUD BARDI, 1990). 
Independente da solução urbanístico-arquitetônica que se apresente, entende-se que o equívoco cometido até o momento não deverá ser repetido no futuro. Também, ignorar as experiências do passado e negar seus valores são posturas que em determinado período já assumimos, e estamos, cada vez mais, certos de que este não é o caminho adequado a ser seguido.

Sendo assim, o futuro do Elevado deverá ser pensado e discutido com cautela, sempre alerta tanto aos perigos, mas também às descobertas e surpresas que poderão se revelar. Entender que a imprevisibilidade é algo positivo quando se aborta a escala urbana, coloca o fator tempo ao favor da construção e do pensamento, como um dos principais agentes produtores da criatividade e ocupação diversa.

Este debate é de tamanha complexidade, que além de carecer de abordagem transdisciplinar dos fenômenos, como mudanças de paradigmas, eliminação do racionalismo que tem pautado a investigação científica em todos os campos, etc., ele também deve dar lugar a criatividade e ao caos, assim como à subjetividade e o desconhecido. Os aspectos globais nele discutidos, podem ter foco mais humanitário e menos capitalista. O Elevado é um exemplo de que

Existem múltiplas globalizações. A econômica, a corporativa, a financeira, a tecnológica. Nota-se nisso tudo certa tendência de desumanização da nossa vida e da nossa subjetividade. Mas outras globalizações também estão em curso, como a da sociedade civil, da defesa dos direitos humanos, das lutas pela preservação do meio ambiente, e essas nos humanizam de maneira profunda. (SASSEN, 2014).

Portanto, com base nos recursos humanos e materiais acessíveis, é necessário alcançar o mais alto grau de compreensão das mais variadas abordagens presentes nesta discussão, a fim de transformar a região em um território referencial do habitat humano, adequado aos modos de vida locais, tanto em qualidade quanto em quantidade.

Desta forma, conclui-se que o projeto do High Line Park tem profunda contribuição para a história de intervenções urbanas em metrópoles 


\section{Revista Nacional de}

Gerenciamento de Cidades

contemporâneas, não só para a cidade de Nova lorque, mas como um estudo de caso único na história das transformações desta escala. Contudo, não deve ser tomado como verdade única, a ser replicada em demais contextos, e sim como possível modelo metodológico de pesquisa, levantamento e integração entre as instâncias pública e privada.

\section{REFERÊNCIAS BIBLIOGRÁFICAS}

ARTIGAS, Rosa; CASTRO, Ana Claudia; MELLO, Joana (2008), Caminhos do Elevado: memória e projetos. São Paulo: Secretaria Municipal de Planejamento - Sempla, Departamento de Estatística e Produção de Informação - Dipro, Imprensa Oficial do Estado de São Paulo/2008.

DAVID, Joshua; HAMMOND, Robert (2011), HIGH LINE: The inside story of New York's City Park in the Sky. Nova lorque: FSG books / 2013.

DECANDIA, Lidia. (2003). O Tempo e o invisível: da cidade moderna à cidade contemporânea. Disponível em: http://www.pucsp.br/margem/pdf/m17ld.pdf. Acesso 23 de março de 2015.

Friends of the High Line, 2008. Disponível em http://www.thehighline.org. Acesso em: 03 de abril de 2015.

GRINOVER, Marina; RUBINO, Silvana, Lina por escrito: textos escolhidos de Lina Bo Bardi. São Paulo: Cosac Naify/ 2009.

HAZARI, P, Designing the High Line. Nova lorque: Firends of the High Line, 2008.

KOOLHAAS, Rem, A cidade genérica (1997). In:Três textos sobre a cidade. Tradução de Luís Santiago Baptista, p. 29-65, Barcelona: GG /2010.

MEJEAN, Thomas. New York. The High Line Park: growing innovative urban projects on a common ground. Tafter Journal. Roma, 2013. Disponível em:

http://www.tafterjournal.it/2013/02/22/new-york-the-high-line-park-growing-innovative-urban-projectson-a-common-ground.pdf. Acesso em 23 de abril de 2015.

Plano Diretor da Cidade de São Paulo, Lei 16.050/2014. Disponível em http://www.prefeitura.sp.gov.br/cidade/secretarias/upload/chamadas/2014-07-31_-_lei_16050__plano_diretor_estratgico_1428507821.pdf. Acesso em 16 de março de 2015.

ROCHA, Paulo Mendes, América, Natureza e Cidade. Com Maria Isabel Villac. São Paulo: Estação Liberdade/2012.

SASSEN, Saskia, Who owns the city?. Urban age Governing Urban Futures Conference. Dehli, India, 2014. Disponível em: https://delhi2014.Isecities.net/newspaper/articles/who-owns-the-city/en$\mathrm{gb} /$. Acesso em 18 de agosto de 2015. 


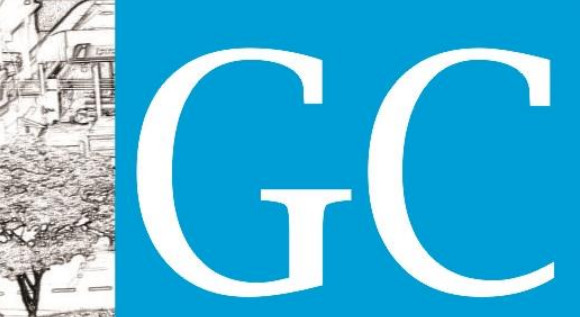

Revista Nacional de Gerenciamento de Cidades

SENNETT, Richard, Carne e Pedra. Traduzido por Marcos Aarão Reis. Terceira edição. Rio de Janeiro: Record/2003.

WAISMAN, Marina. O interior da história: historiografia arquitetônica para uso de latinoamericanos. [Tradução de Anita Di Marco]. São Paulo: Perspectiva/2013.

WISNIK, Guilherme, Estado Crítico: à deriva nas cidades. São Paulo: Publifolha/ 2009. 